\title{
CT and MRI Findings of Head and Neck Masson's Tumor: A Rare Case Report and Systematic Review of the Literature
}

This article was published in the following Dove Press journal:

Reports in Medical Imaging

\begin{abstract}
Caterina Giannitto,' Giuseppe Mercante, ${ }^{2,3}$ Giuseppe Spriano, ${ }^{2,3}$ Rossella Natoli, ${ }^{4}$ Francesca Gaino, (D) ${ }^{2}$ Ludovica Lofino, (D) ${ }^{1}$ Andrea Alessandro Esposito, (iD) ${ }^{5}$ Nino Giannitto, ${ }^{6}$ Giulia Vatteroni,' Barbara Fiamengo, ${ }^{7}$ Antonello Vidiri, ${ }^{8}$ Letterio Salvatore Politi, ${ }^{1,3, *}$ Luca Balzarini ${ }^{1 * *}$

'Department of Diagnostic Radiology, Humanitas Clinical and Research Center IRCCS, Milan, Italy; ${ }^{2}$ Otorhinolaryngology Unit, Humanitas University, Humanitas Clinical and Research Center - IRCCS, Milan, Italy; ${ }^{3}$ Department of Biomedical Sciences, Humanitas University, Pieve Emanuele, Milan, Italy; ${ }^{4}$ University of Milano-Bicocca, Milan, Italy; ${ }^{5}$ Department of Diagnostic Radiology, Foundation I.R.C. C.S Ca' Granda Ospedale Maggiore Policlinico Hospital, Milan, Italy; ${ }^{6}$ Department of Pediatric Sciences, University of Messina, Messina, Italy; ${ }^{7}$ Pathology Unit, Humanitas University, Humanitas Clinical and Research Center IRCCS, Milan, Italy; ${ }^{8}$ Radiology and Diagnostic Imaging Department, IRCCS Regina Elena National Cancer Institute, Rome, Italy

*These authors contributed equally to this work
\end{abstract}

Correspondence: Caterina Giannitto Department of Diagnostic Radiology, Humanitas Clinical and Research Center IRCCS, Via A. Manzoni 56, Rozzano, Milan, 20089, Italy

Tel +39282247529

Email caterina.giannitto@humanitas.it

Andrea Alessandro Esposito Department of Diagnostic Radiology Foundation I.R.C.C.S Ca' Granda Ospedale Maggiore Policlinico Milano, Via F. Sforza 35, Milan, 20I2I, Italy Tel +393475476654

Email andrea.esposito@policlinico.mi.it
Background: Masson's tumor (MT) is a rare benign vascular disease. In literature, detailed description of its radiological findings is not available and functional imaging such as diffusion weighted (DW)-MRI has never been described. We aim to summarize the CT and MRI findings in our representative case and to conduct a systematic review of the literature.

Case Presentation: We reported a 54-year-old ex-smoker male patient who presented with a nodular mass to the left cheek. He denied any previous trauma. CT examination performed on initial presentation revealed a well circumscribed solid oval mass with soft tissue density, a calcified focus and no significative contrast enhancement after contrast administration. MRI showed a well circumscribed solid oval mass, with intermediate T2 signal intensity with areas of high T2 signal intensity and the presence of peripheral high-flow serpentine vessels, low T1 signal intensity. The mass showed a non-enhancing area with enhancing vessels after intravenous contrast administration. We surveyed CT and MRI findings of head and neck MT of English and French language papers, published from 1981 to 2019, together with our representative case. We included articles with a description of CT and/or MRI findings of head and neck MT.

Conclusion: We have experienced one case and have evaluated imaging findings through systematic review. Only 36 articles were eligible. CT and MRI findings were reported in 27 and 23 articles, respectively. To date, no diffusion weighted imaging (DWI)-MRI findings have been described. The most frequent findings in CT were a well-defined mass with high or soft tissue density. The most frequent MRI findings were a non-homogeneous signal intensity in T1 and T2 weighted sequences, with foci of hyperintensity, multiple septations or flow voids. After contrast administration, the enhancement could be homogeneous, non-homogeneous, nodular or peripheral. In our case, we found a non-homogeneous hyperintensity in DWI-MRI with an area of restricted diffusion and low apparent diffusion coefficient (ADC) was observed $\left(0.963 \times 10^{-3} \mathrm{~mm}^{2} / \mathrm{s}+\backslash-0.12 \mathrm{SD}\right)$. The imaging characteristics cannot provide a pre-operative identikit of MT and surgical removal is necessary to accurately differentiate it from malignant angiosarcoma but radiological evaluation is useful in surgical planning.

Keywords: Masson's tumor, case report, computed tomography, magnetic resonance imaging, diffusion weighted imaging

\section{Background}

Masson's tumor (MT), also known as intravascular papillary endothelial hyperplasia (IPEH) or Masson's hemangioma, is a rare benign vascular disease with an exuberant endothelial proliferation in blood vessels that usually affects the 
extremities including head, neck and upper limbs. ${ }^{1,2}$ It is most frequent in the digits and in rare circumstances, lesions have been observed in the abdominal organs or in intracranial aneurysms. ${ }^{3}$

The lesion can arise from normal blood vessels, and in this case it is referred to as a "pure form", or in a preexisting vascular lesion, the so-called "mixed form".

It is slightly more frequent in women (1.3:1). Its aetiology is generally considered as multifactorial even though in $30 \%$ of cases it arises after a local trauma or it is associated with vascular conditions (hemangiomas, vascular malformations). ${ }^{4}$

Radiological diagnosis of MT is usually challenging, due to the infrequent occurrence in head and neck and the similarity with vascular tumors like low grade angiosarcoma or Kaposi's sarcoma.

In particular, it is not a typical pathologic condition of the buccal space and the knowledge of the expected CT and MR imaging findings can be helpful for the radiologist on differential diagnosis.

However, histology has to be confirmed by surgical removal and pathology.

We show here a representative case of MT of left buccal space, of which diagnostic and therapeutic experience remain limited. Further, we surveyed Computed tomography (CT) and Magnetic Resonance Imaging (MRI) findings of head and neck MT in English and French language papers, published from 1981 to 2019, to evaluate if the imaging characteristics of MT can suggest the diagnosis pre-operatively.

\section{Case Presentation}

The patient provided written informed consent for publication of this case report and accompanying images. This case presentation was accepted by the Ethics Committee of Humanitas Clinical and Research Center and it was conducted in accordance with the principles of the Declaration of Helsinki.

The subject is a 54-year-old ex-smoker male patient who presented at our ENT out-patient clinic in October 2019 with an apparently painless swelling on the left cheek, without facial palsy, complaining of a mass that appeared four months previously. He suffered from hypertension and dyslipidemia and denied any previous trauma to the cheek. Twenty five years ago he has undergone surgical removal of back lipoma and fifteen years ago a reconstruction of the anterior cruciate ligament.
The clinical examination revealed a mass about $3 \mathrm{~cm}$ on the left cheek, of skin colour and hard consistency, which was not attached to the subcutaneous tissue or to the skin. The lesion had been increasing slightly in size over the last months.

Ultrasound examination performed in another Hospital in August 2019 revealed a hypo-anechoic oval mass about $30 \times 15 \mathrm{~mm}$ with thin septa and a vascular pole inside.

In October 2019, he underwent ultrasound-guided trucut $(18 \mathrm{G})$ needle biopsy and pathology examination revealed neoplasm of vascular origin.

CT examination was performed in October 2019 using a REVOLUTION CT scanner from GE Medical Systems (Illinois, United States), imaging was initiated 70 seconds after the start of intravenous administration of $100 \mathrm{~mL}$ of nonionic iodinated contrast agent (iopamidol, Imeron 400; Bracco-Altana Pharma, Konstanz, Germany) through an antecubital vein at a flow rate of $2 \mathrm{~mL} / \mathrm{s}$. Examination parameters were as follows: tube voltage $120 \mathrm{kVp}$, reference current-time product of $79 \mathrm{mAs}$ per rotation; rotation time, 0.5 seconds; pitch, 0.9 ; collimation, $2 \times 64 \times 0.6 \mathrm{~mm}$. We performed a late scan at 80 seconds with tube voltage of $80 \mathrm{kVp}$ to increase iodine attenuation and image contrast of soft-tissue structures.

CT revealed a well circumscribed solid oval mass about $38 \mathrm{~mm}$ with soft tissue density, a calcified focus and no significative contrast enhancement after contrast administration (Figure 1) in the left buccal space.

A month later, he underwent MRI examination performed using a 1.5 Tesla MAGNETOM Avanto (Siemens Healthcare, Erlangen), with TSE T1-weighted sequences (TE $9.9 \mathrm{~ms}$, TR $646 \mathrm{~ms}$, Flip angle 220 , Field of view $220 \mathrm{~mm}$, slice thickness $3 \mathrm{~mm}$ ), BLADE T2-weighted sequences (TE $141 \mathrm{~ms}$, TR $8.0 \mathrm{~ms}$, Flip angle 90 , Field of view $220 \mathrm{~mm}$, slice thickness $3 \mathrm{~mm}$ ), 3D Volumetric interpolated breath-hold examination (VIBE) sequence (TE $1.6 \mathrm{~ms}$, TR $4.4 \mathrm{~ms}$, Flip angle $13^{\circ}$, Field of view $240 \mathrm{~mm}$, slice thickness $0.8 \mathrm{~mm}$ ).

MRI showed a well circumscribed solid oval mass about $39 \mathrm{~mm}$, with intermediate $T_{2}$ signal intensity with areas of high T2 signal intensity and the presence of peripheral high-flow serpentine vessels (low signal intensity on $T_{2}$ weighted images) (Figure $2 \mathrm{~A}$ ) and low $T_{1}$ signal intensity (Figure 2B). The mass showed a non-enhancing area with enhancing vessels after intravenous contrast administration (Figure 2C). In depth, it showed extension in the masticatory space, where it imprinted the medial pterygoid muscle. 


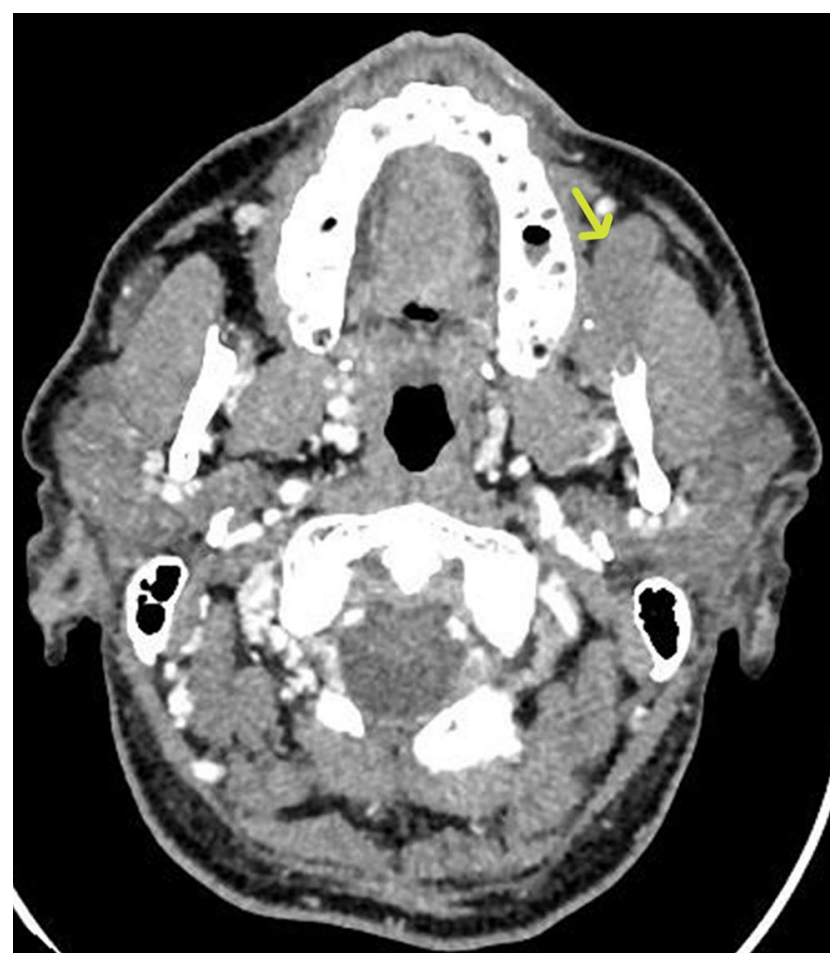

Figure I CT findings of our representative case of a 54-year-old man with MT in left buccal space. Axial contrast-enhanced CT image demonstrates a well circumscribed solid oval mass (yellow arrow) with soft tissue density, a calcified focus and no significative contrast enhancement after contrast medium administration.

Diffusion Weighted Imaging (DWI)-MRI is a functional tool that can help to differentiate benign from malignant lesions. In this case, DWI was performed with 3-scan trace approach at $\mathrm{b}$ values of 50,500 and $1000 \mathrm{~s} / \mathrm{mm}^{2}$. The mass showed a non-homogeneous hyperintensity on trace images with an area of restricted diffusion and low Apparent Diffusion Coefficient (ADC) in the corresponding map (mean ADC value was $0.963 \times 10^{-3} \mathrm{~mm}^{2} / \mathrm{s}$ ) (Figure 3).

Imaging suggested a mass of the left buccal space with morphological pattern compatible with the histological results of vascular neoplasm. The signal restriction in DWIMRI, that is possible expression of thrombus or malignant degeneration, suggested further histological characterization on the entire volume of the lesion after surgical removal.

The lesion had been totally excised by trans-oral approach in December 2019. It appeared covered by the Bichat's fat pat and it was richly vascularized and in continuity with the pterygoid muscle.

The final pathologically diagnosis was MT.

On the pathologic specimen from surgery, a mass containing dilatated small caliber vessels was seen in addition to a thrombus and anastomosing network of little vessels with some fibrous septa. The mass was surrounded by muscular fibers (Figure 4).

At first follow-up visit, one month after surgery, there have not been post-operative complications. Five months after surgery no clinical signs of tumor recurrence were found and the patient has not undergone any treatment; his prognosis was good.

\section{Discussion}

MT, described for the first time in 1923 by Masson, ${ }^{5,6}$ may mimic other benign lesions including mucocele, pyogenic
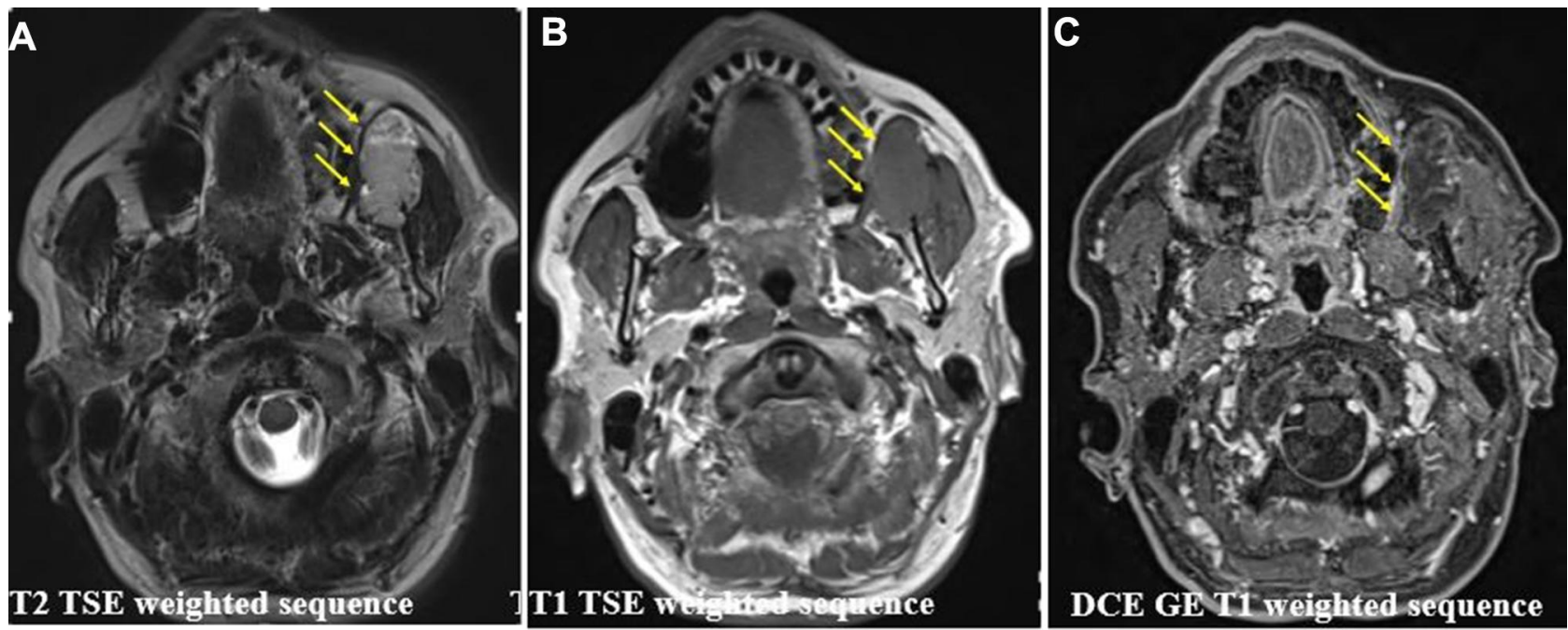

Figure 2 MRI findings of our representative case of a 54-year-old man with MT in left buccal space. (A) Axial T2 sequence showed a well circumscribed solid oval mass (yellow arrows) with intermediate signal intensity with areas of high signal intensity and the presence of peripheral high-flow serpentine vessels. (B) Axial TI sequence showed low signal intensity of the oval lesion (yellow arrows). (C) The mass (yellow arrows) showed a non-enhancing area with enhancing vessels after intravenous contrast administration. 


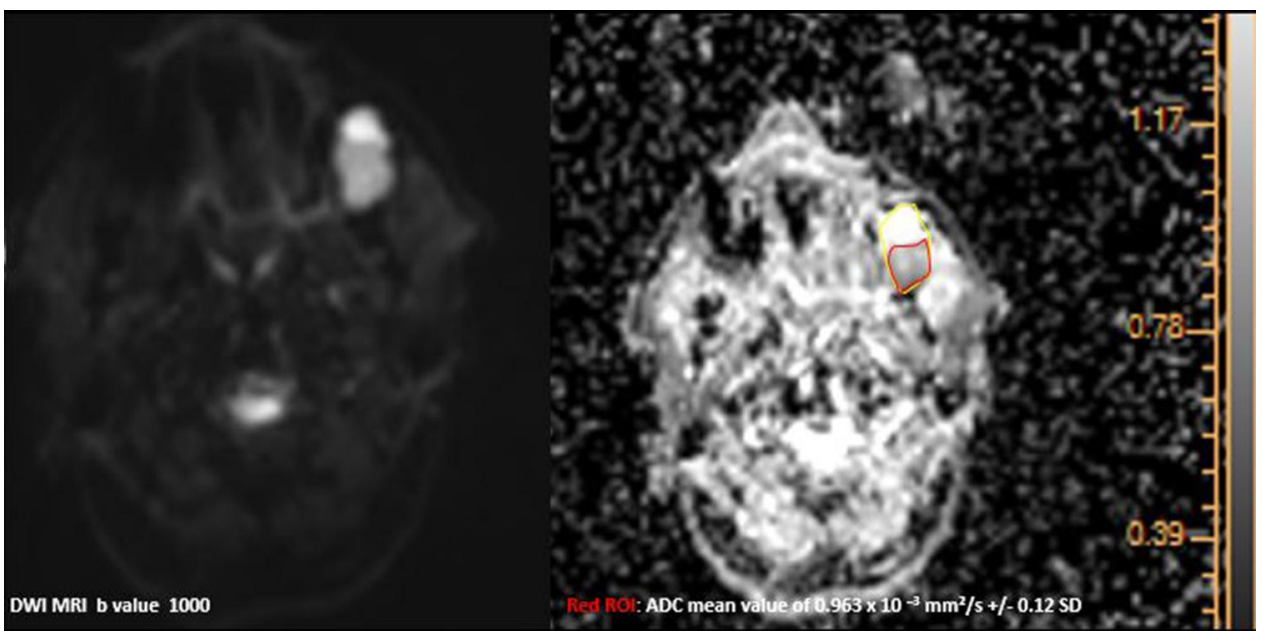

Figure 3 DW-MRI findings of our representative case of a 54 -year-old man with MT (yellow circle) in left buccal space. DWI sequences at 1000 s/mm ${ }^{2}$ showed a nonhomogeneous hyperintensity in diffusion weighted sequences with an area of restricted diffusion and low apparent diffusion coefficient (ADC) mean value of $0.963 \times 10^{-3}$ $\mathrm{mm}^{2} / \mathrm{s}$ in the corresponding map, Red region of interest (ROI).

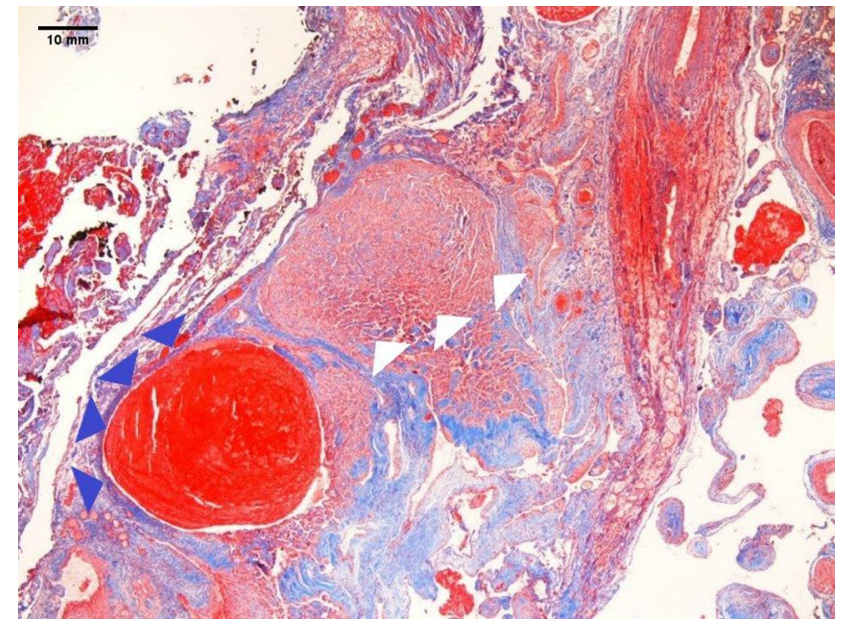

Figure 4 Pathologic specimens (Masson stain 4x) of our representative case of a 54-year-old man with MT in left buccal space. On the pathologic specimen from surgery a mass containing vessel of dilatated small calibre (white triangles) was seen in addition to a thrombus (purple triangles) and anastomosing network of little vessels, some fibrous septa and muscular fibers around the lesion.

granuloma and hemangioma and malignant neoplasms such as angiosarcoma and Kaposi's sarcoma. ${ }^{3}$ The most frequent locations in head and neck were dermis, lip, tongue and buccal mucosa, followed by thyroid, orbit, parotid gland, masseter muscle, nose, sinus, mandible, pharynx and central nervous system. ${ }^{7}$

Histologically, MT is characterized by formation of papillary structures lined by hyperplastic endothelial cells in a thrombosed vascular lumen. ${ }^{3}$ These pathologic features do not allow to easily differentiate MT from angiosarcoma and other benign and malignant lesions, ${ }^{8}$ like haemangioma, ${ }^{9}$ thrombosed aneurysm, ${ }^{10}$ and Kaposi's sarcoma. ${ }^{11-13}$
MT treatment is less invasive than malignant tumors, such as angiosarcoma that is able to metastasize and may not be fully eradicated by localized surgical removal. Preoperative radiological diagnosis can be difficult as it has similar CT and MRI appearance to other benign or malignant lesions. Depending on its location, MT should be differentiated from other head or neck soft tissue tumors. In particular, lesions in the orbits should be differentiated from inflammatory pseudotumor, giant cell angiofibroma, rhabdomyosarcoma. Solitary fibrous tumors, sinonasal glomus tumors and sarcomas (fibrosarcoma, rhabdomyosarcoma, malignant fibrous histiosarcoma, leiomyosarcoma) should be included in the differential diagnosis of MT in the sinonasal cavities. MT of the skin should be distinguished from dermatofibroma, dermatofibrosarcoma, while inter- or intramuscular MT from synovial sarcoma, myositis ossificans, pleomorphic sarcoma, liposarcoma, rhabdomyosarcoma.

In consideration of the rarity of MT, we reported our experience and evaluated image findings through systematic review to identify key features that could help in preoperative radiological diagnosis.

A comprehensive literature search of English and nonEnglish studies using PubMed was completed up to January 2020 to identify studies evaluating head and neck MT. The following keywords in different combinations were used: "intravascular papillary endothelial hyperplasia" OR ", IPEH" OR "Masson hemangioma" OR "Masson pseudoangiosarcoma" OR "Masson tumor".

The initial search yielded 1745 hits, whose titles and abstracts were screened for eligibility. We removed 1477 
of these because there was not a description of MT cases and we screened 268 studies. Out of these, full text was available in 248 articles, but only 36 were eligible.

There were no original articles focusing on CT and MRI accuracy and technique with valid results. All the articles were case reports or clinical series published between 1981 and 2019 (Table 1). Among the 36 articles, we found 37 cases (14 M, $23 \mathrm{~F}$ ) of patients with head and neck MT, who underwent CT and lor MRI examination.

The median age was 34.79 (range 0-70). We found 9 MT cases in the head and skull base, ${ }^{16,18,31-33,35,40,43} 6$ in the orbit,3,14,20,26,29,37 7 cases in paranasal sinuses, ${ }^{8,9,17,25,28,44,46} 1$ case within the parotid gland, ${ }^{41} 2$ in parapharyngeal space, ${ }^{19,22} 2$ in larynx and hypopharynx, ${ }^{27,39} 4$ in buccal space or cheek, $23,24,34,36$ 1 in submandibular space, ${ }^{42} 1$ in the lip, ${ }^{30} 1$ in the mandible, ${ }^{38} 3$ in the neck. ${ }^{15,21,45}$

CT examination was reported in 27 out of 36 articles and in 28 patients, but CT findings were described in 23 articles. MR examination was reported in 23 out of 36 articles and in 23 patients, but MR findings were described in 19 articles. To date, no Diffusion Weighted Imaging (DWI)-MRI findings were described.

Our representative case would be the first one reported with description of CT, MRI and DWI-MRI findings.

Summarizing the descriptions reported, the most frequent CT findings were a well-defined mass with high or soft tissue density, with calcifications in some cases. After contrast medium administration, the enhancement could be homogeneous, non-homogeneous, nodular or peripheral. Bone erosion and lytic lesion were reported in MT of paranasal sinuses and scalp.

The most frequent MRI findings were a well-defined mass with a non-homogeneous signal intensity on T1 and T2 weighted sequences. In particular, MRI showed hypoisointensity in $\mathrm{T} 1$ sequences with foci of hyperintensity (hemorrhage) and hyperintensity on T2 sequences with multiple septations or flow voids (vascular channels). The MRI contrast enhancement is similar to that reported in CT. Bone erosion and fatty infiltration were reported in some cases.

The most frequent CT and MRI findings can mimic angiosarcoma and Kaposi's sarcoma. ${ }^{47}$ The different MRI and CT patterns found in literature could represent the different stages of thrombus organization. In fact, older MT presents growth of endothelial cells, smooth muscle cells, and fibroblasts into the fibrin-rich thrombus. Over time, MT is characterized by formation of capillary channels that may anastomose to create conduits from one end of the thrombus to the other, reestablishing to some extent the continuity of the original lumen. ${ }^{3}$ This could explain the presence of high and low flow serpentine vessels seen in the MRI findings reported in the literature and in our case. If the thrombus is recanalized, it becomes a vascularized mass of connective tissue, incorporated in the subendothelial layer of the vessel wall. This could explain the presence of homogeneous or peripheral contrast enhancement. In late stage, the thrombus is replaced by a fibrous nodule originating from mesenchymal cell contraction. ${ }^{3}$

DWI may also play a role in the differentiation of head and neck malignant and benign tumors, because tumoral Apparent Diffusion Coefficient (ADC) values tend to vary depending on the stage of tumor cell differentiation, the degree of tumor cellularity, the presence of necrotic tissue, and the degree of degenerative change in interstitial tissues. Malignant soft tissue tumors usually have low ADC values, which are represented as low signal intensity on ADC maps, whereas benign tumors tend to have higher ADC values. ${ }^{48-51}$

In particular, it has been shown that the ADC correlates with tumor cellularity in soft tissue sarcomas and it is lower in malignant non myxoid soft tissue tumors than in benign tumors. $^{52-54}$

In the case presented, MT showed mixed areas of restricted diffusivity, with a mean $\mathrm{ADC}$ value of $0.963 \times$ $10^{-3} \mathrm{~mm}^{2} / \mathrm{s}$ that overlaps the mean ADC value range $0.41-$ $1.45 \times 10^{-3} \mathrm{~mm}^{2} / \mathrm{s}$ of angiosarcoma with solid portions, reported by Sero et al. ${ }^{55}$ The area of non-restricted diffusion could be interpreted as a low cellularity area. This could limit the accuracy of the technique in distinguishing between the two conditions. It is reported that angiosarcomas with predominantly dilated vascular spaces may correspond to low cellularity with no diffusion restriction, and angiosarcomas with predominantly solid portions may correspond to high cellularity with diffusion restriction. Moreover, fibrosis, necrosis and hemorrhage are frequently encountered in angiosarcomas and low ADC values may be induced by hematoma or fibrosis. In our case, histology showed a growth of papillary structures lined by hyperplastic endothelial cells into the fibrin-rich thrombus and capillary channels (Figure 4). Low ADC values may have been induced by hyperplastic endothelial cell proliferation or by the latest stage of fibrin-rich thrombus. ${ }^{56}$ The region with no DWI restriction may correspond to capillary channels.

Histomorphological findings (the lack of necrosis and mitosis and presence of organizing thrombi) in conjunction 


\begin{tabular}{|c|c|c|c|c|c|c|c|c|c|c|c|c|c|c|}
\hline 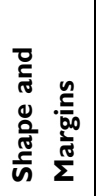 & 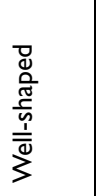 & 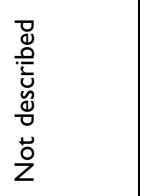 & 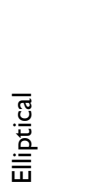 & 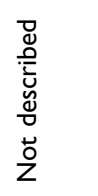 & 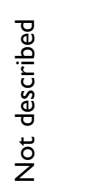 & \multicolumn{3}{|l|}{ 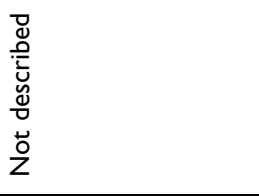 } & 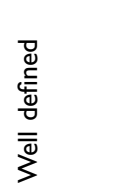 & 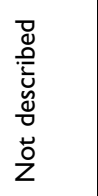 & 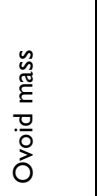 & \multicolumn{3}{|l|}{ 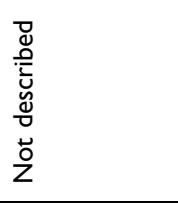 } \\
\hline 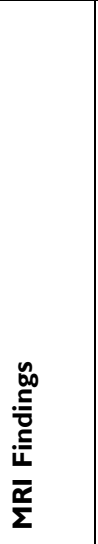 & 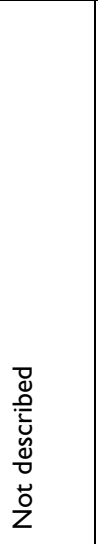 & 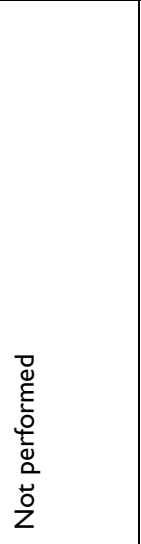 & 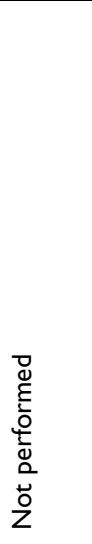 & 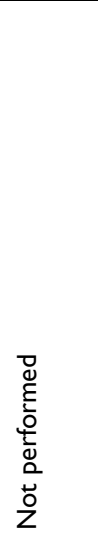 & 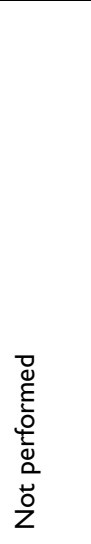 & 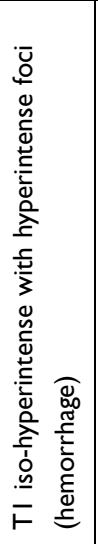 & 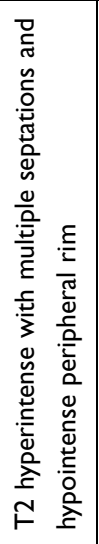 & 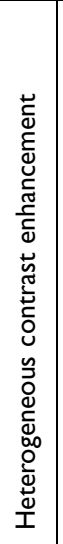 & 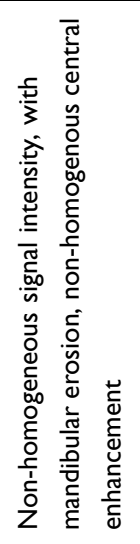 & 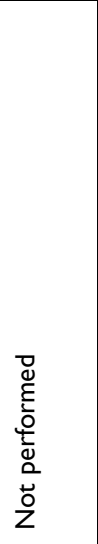 & 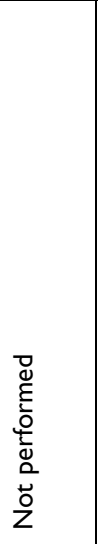 & 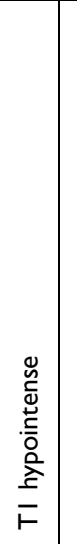 & 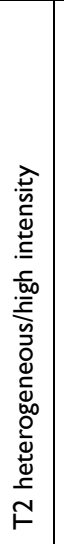 & 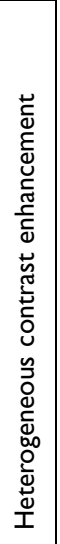 \\
\hline 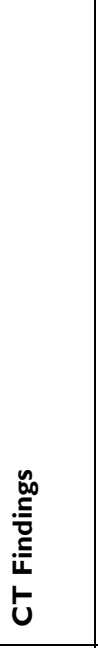 & 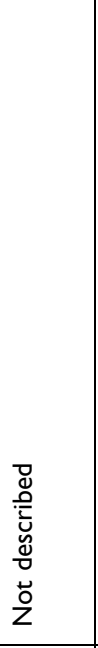 & 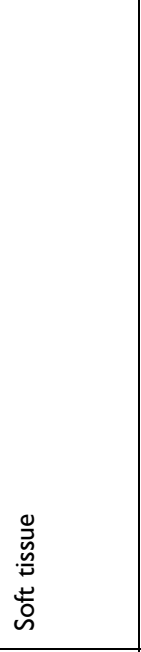 & 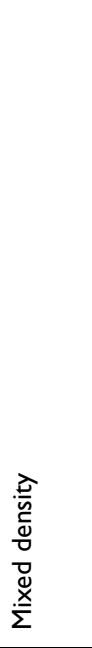 & 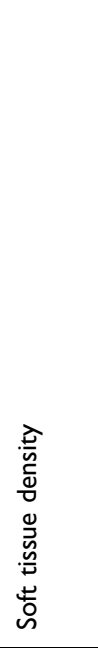 & 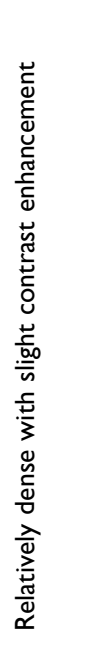 & 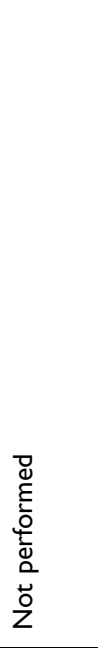 & & & 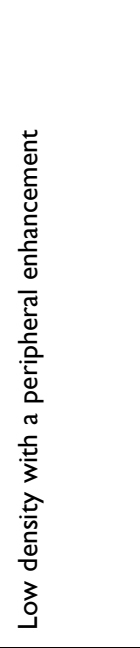 & 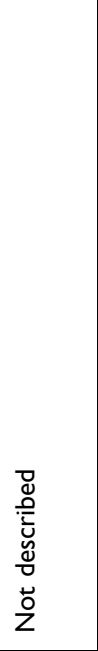 & 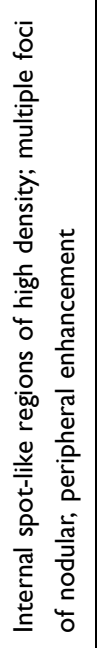 & 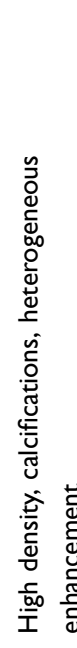 & & \\
\hline 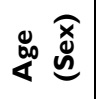 & 今ે & 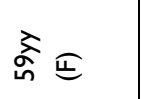 & 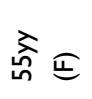 & $\underline{\Sigma} \underline{\Sigma}$ & 斑 $\widehat{\Sigma}$ & 商匹 & & & స્心ે $\widehat{\Sigma}$ & 商星 & હે $\widehat{\Sigma}$ & 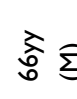 & & \\
\hline 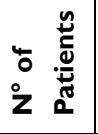 & - & - & - & - & - & - & & & - & - & - & - & & \\
\hline 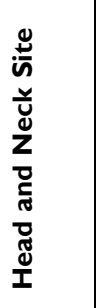 & 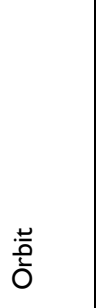 & 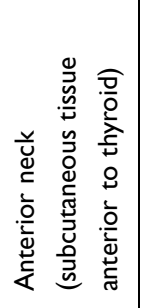 & 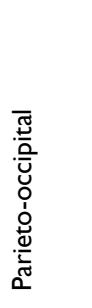 & 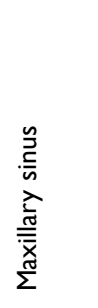 & 廌 & 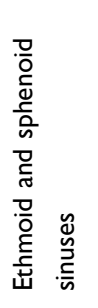 & & & 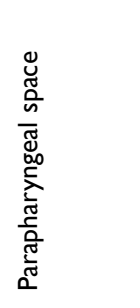 & 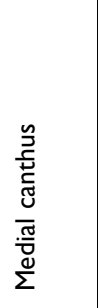 & 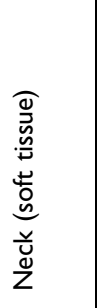 & 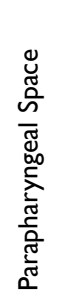 & & \\
\hline 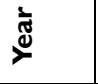 & $\underline{\alpha}$ & $\underset{\Xi}{\stackrel{\Xi}{\alpha}}$ & $\stackrel{\widehat{\infty}}{\underline{\alpha}}$ & $\bar{\sigma}$ & 兄 & ષ્̀ & & & চ্ণ & ষ্ণ & ڤ̊̀ & ષ્તે & & \\
\hline 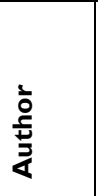 & 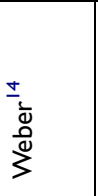 & 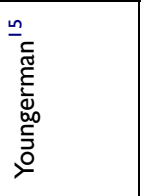 & 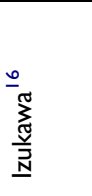 & 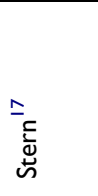 & 焉 & $\begin{array}{l}{ }^{\circ} \overline{0} \\
\Sigma \\
\Sigma\end{array}$ & & & 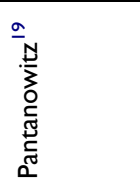 & 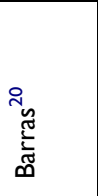 & $\begin{array}{l}\bar{r}_{\bar{s}} \\
\stackrel{5}{J}\end{array}$ & $\begin{array}{l}\pi_{0} \\
\stackrel{0}{0} \\
\frac{\xi}{\bar{E}} \\
\frac{-\underline{y}}{Z}\end{array}$ & & \\
\hline
\end{tabular}




\begin{tabular}{|c|c|c|c|c|c|c|c|c|c|c|c|c|c|}
\hline 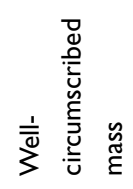 & 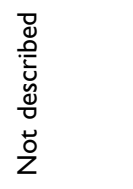 & 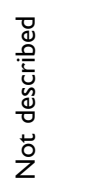 & 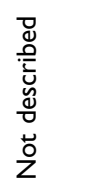 & 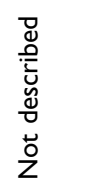 & 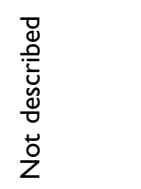 & 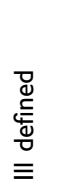 & 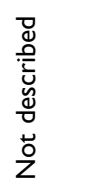 & & 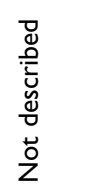 & $\begin{array}{l}\frac{0}{d} \\
\frac{c}{c} \\
\frac{d}{0} \\
\overline{\overline{0}} \\
3\end{array}$ & & & 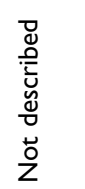 \\
\hline 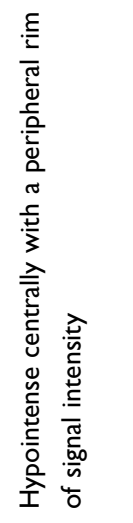 & 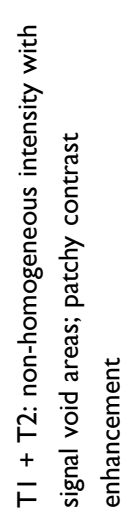 & 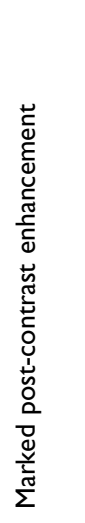 & 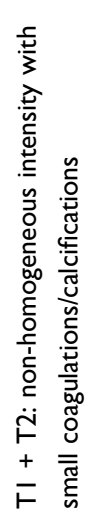 & 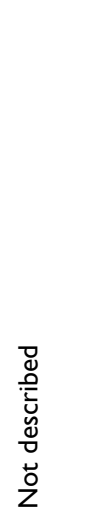 & 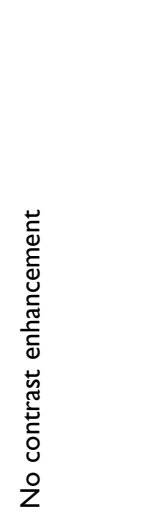 & 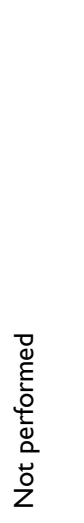 & 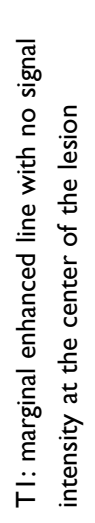 & 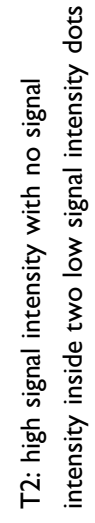 & 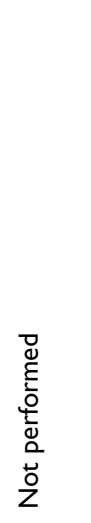 & 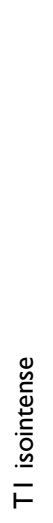 & 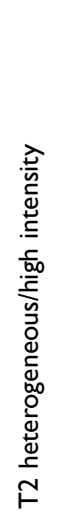 & 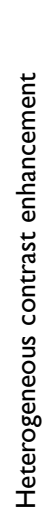 & 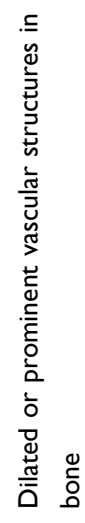 \\
\hline 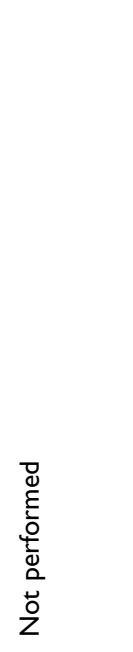 & 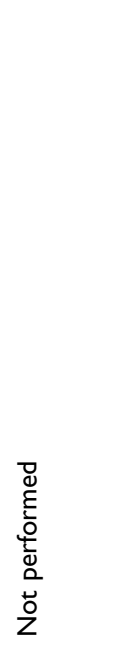 & 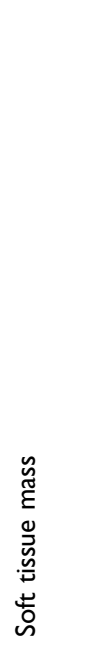 & 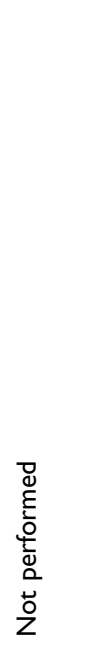 & 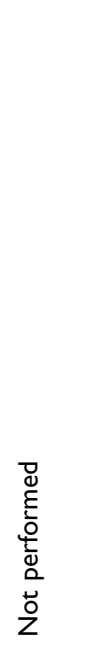 & 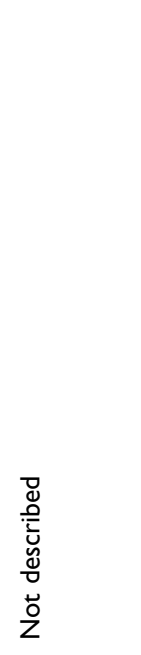 & 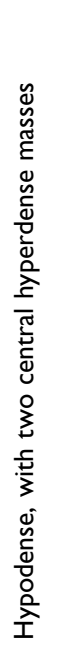 & 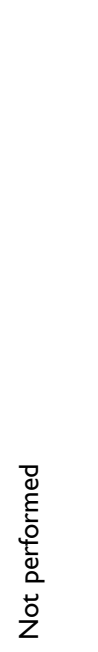 & & 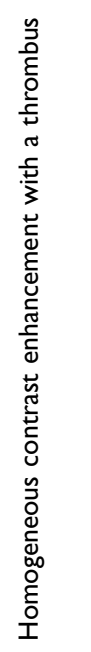 & 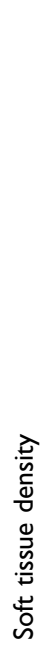 & & & 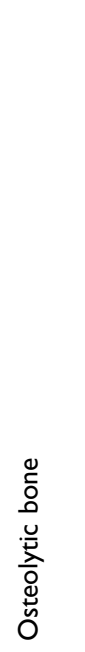 \\
\hline 突药 & 离茂 & 䒽茂 & 畣茂 & 离茂 & 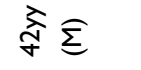 & 斈芒 & 突茂 & & 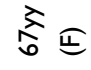 & 초 & & & 斑 $\widehat{\Sigma}$ \\
\hline- & - & - & - & - & - & - & - & & - & - & & & - \\
\hline 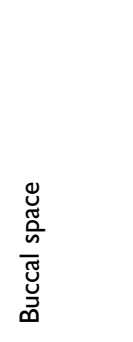 & 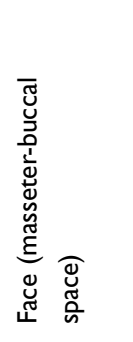 & 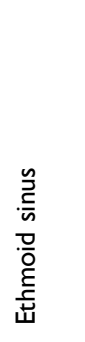 & to: & 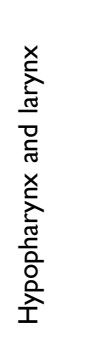 & 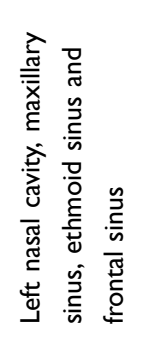 & 䓂 & 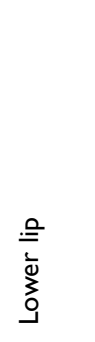 & & 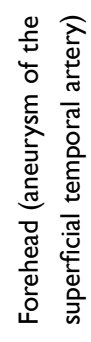 & 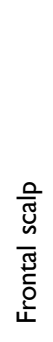 & & & 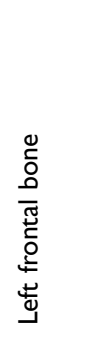 \\
\hline ర્సે & ర્ণ & ఫे & 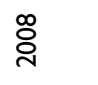 & ्ֻస & ઠे & 을 & 음 & & $\bar{i}$ & $\stackrel{\sim}{\bar{N}}$ & & & $\stackrel{\sim}{\stackrel{N}{N}}$ \\
\hline 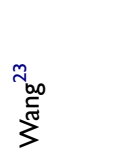 & 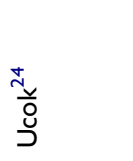 & $\begin{array}{l}\stackrel{n}{\widetilde{T}} \\
\stackrel{0}{0} \\
\stackrel{\circ}{1} \\
\stackrel{0}{1}\end{array}$ & 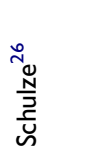 & 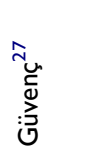 & 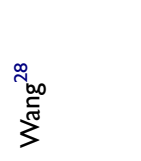 & 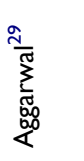 & 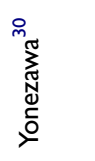 & & 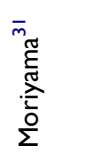 & 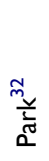 & & & $\tilde{m}_{\mathscr{\Xi}}$ \\
\hline
\end{tabular}




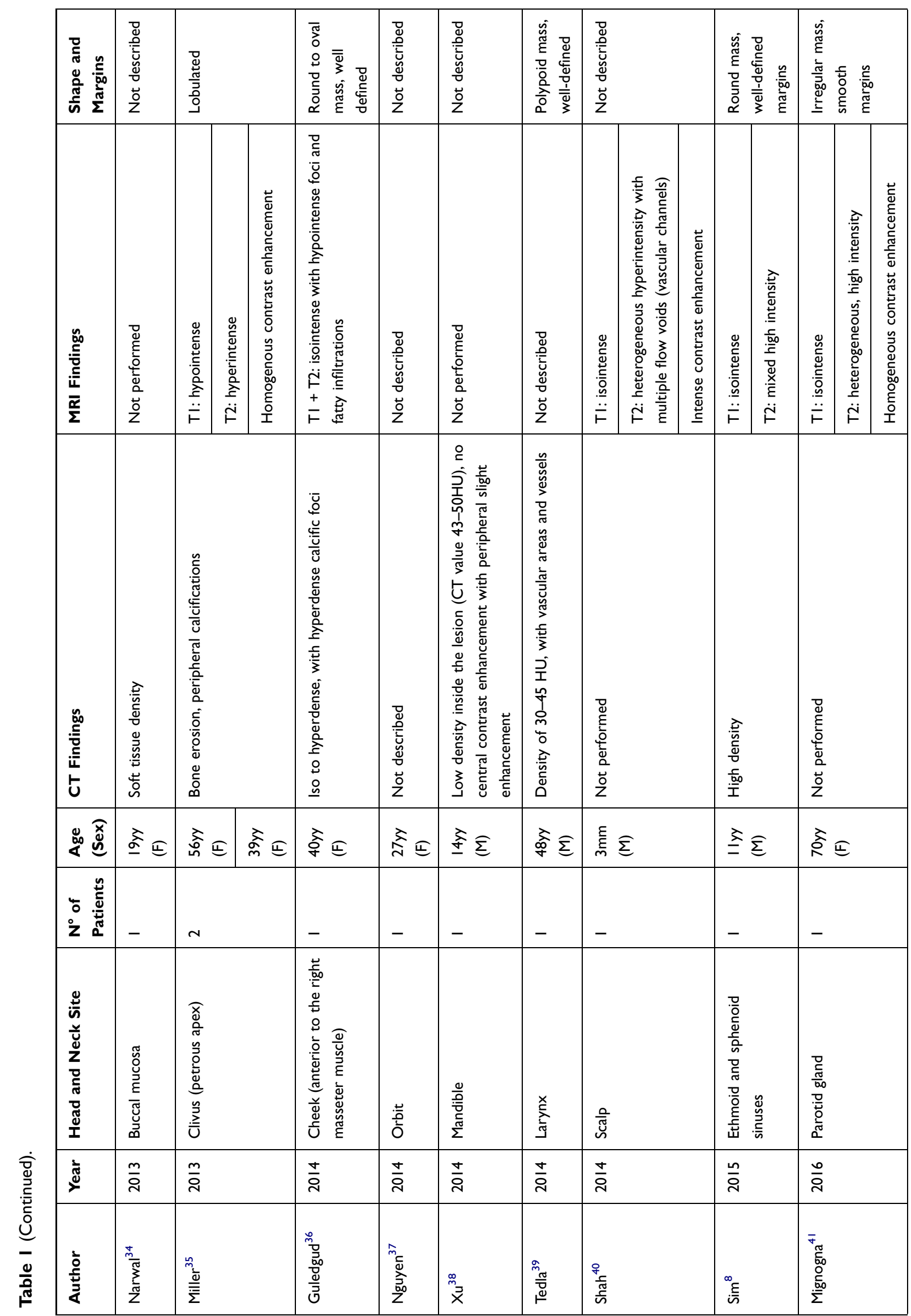




\begin{tabular}{|c|c|c|c|c|c|c|c|c|}
\hline 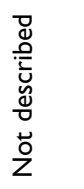 & 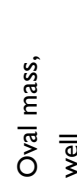 & 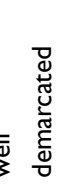 & 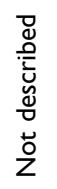 & & & 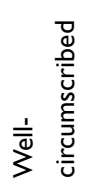 & 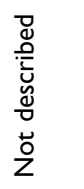 & 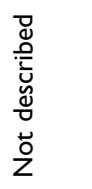 \\
\hline 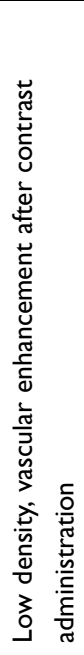 & 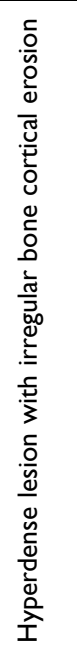 & & 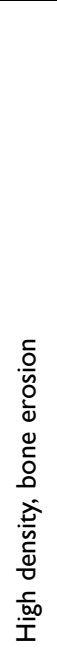 & & & 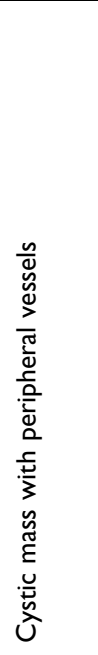 & 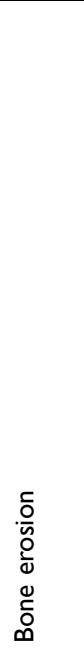 & 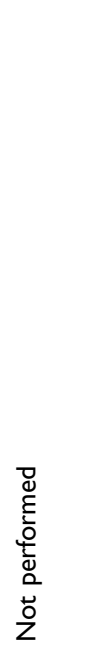 \\
\hline 商 $\mathbb{E}$ & 突 & & సิ & & & 於 $\bar{\Sigma}$ & 命 $\widehat{\Sigma}$ & 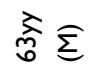 \\
\hline- & - & & - & & & - & - & - \\
\hline 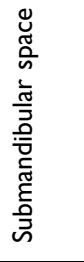 & $\stackrel{\text { 号 }}{\tilde{\omega}}$ & & 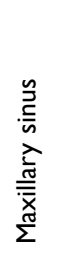 & & & 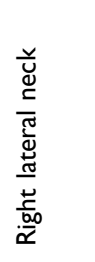 & 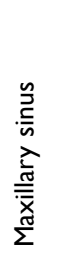 & 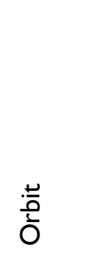 \\
\hline$\overline{\bar{N}}$ & $\bar{i}$ & & $\frac{\infty}{\grave{N}}$ & & & $\frac{\circ}{i}$ & $\frac{\sigma}{\rho}$ & $\frac{a}{\grave{n}}$ \\
\hline 言 & 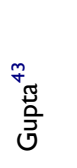 & & 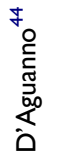 & & & 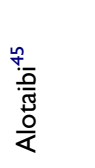 & 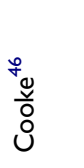 & 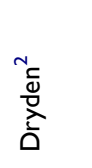 \\
\hline
\end{tabular}


with immunohistochemical staining (CD31 and CD34) of the entire lesion can differentiate MT from angiosarcoma and other malignant head and neck soft tissue tumors.

Currently, no standard treatment of MT had been established, and localized lesion has been usually treated with radical resection. Radical excision was performed in our case and the prognosis was good.

According to literature data and our experience, a preoperative identikit of MT based only on imaging is not achievable and surgical removal is necessary to accurately differentiate it from malignant angiosarcoma.

Despite this, pre-operative radiological evaluation is useful in surgical planning, suggesting a low aggressive behavior more compatible with a benign tumor like MT or low grade angiosarcoma than malignant lesion, preventing unnecessary aggressive surgical approach.

In summary, the present case and literature review suggest that MT may show following imaging features: (1) high or soft tissue density in CT examination, with calcifications in some cases; (2) hypo-isointensity in T1 sequences with foci of hyperintensity (hemorrhage) and hyperintensity on $\mathrm{T} 2$ sequences with multiple septations or flow voids in MRI examination; (3) mixed presence areas of restricted diffusivity in DW-MRI; (4) homogeneous, non-homogeneous, nodular or peripheral contrast enhancement; 5) bone erosion and lytic lesion in some cases.

We hope that our report provide further information for the diagnosis, classification and treatment of the disease in the future.

\section{Abbreviations}

CT, computed tomography; MRI, magnetic resonance imaging; DWI, diffusion weighted imaging.

\section{Acknowledgment}

Salvatore Politi and Luca Balzarini share senior authorship.

\section{Disclosure}

The authors report no conflicts of interest in this work.

\section{References}

1. Tarallo M, Spagnoli AM, Fino P, Lo Torto F, Scuderi N. Masson's tumor: a soft tissue tumor simulating a tendon cyst: case report. $G$ Chir. 2012;33(1-2):34-37.

2. Dryden SC, Marsili S, Meador AG, Randall MB, Fowler B. Intravascular papillary endothelial hyperplasia of the orbit: a case of Masson's tumor. Cureus. 2019;11:e6266.
3. Akdur NC, Donmez M, Gozel S, Ustun H, Hucumenoglu S. Intravascular papillary endothelial hyperplasia: histomorphological and immunohistochemical features. Diagn Pathol. 2013;8(1):167. doi:10.1186/1746-1596-8-167

4. Sasso SE, Naspolini AP, Milanez TB, Suchard G. Masson's tumor (intravascular papillary endothelial hyperplasia). An Bras Dermatol. 2019;94:620-621. doi:10.1016/j.abd.2019.09.013

5. Buchner A, Merrell PW, Carpenter WM, Leider AS. Oral intravascular papillary endothelial hyperplasia. J Oral Pathol Med. 1990;19 (9):419-422. doi:10.1111/j.1600-0714.1990.tb00871.x

6. Murugaraj V, Kingston GT, Patel M, Anand R. Intravascular papillary endothelial hyperplasia (Masson's tumour) of the oral mucosa. Br J Oral Maxillofac Surg. 2010;48:e16-7. doi:10.1016/j.bjoms.2009.12.009

7. Kosmehl H, Katenkamp D, Langbein L, Trethon A. Papillary endothelial hyperplasia. Diagnosis and differential diagnosis. Zentralbl Allg Pathol. 1986;131:249-257.

8. Sim SY, Lim YC, Won KS, Cho KG. Thirteen-year follow-up of parasellar intravascular papillary endothelial hyperplasia successfully treated by surgical excision: case report. $J$ Neurosurg Pediatr. 2015;15(4):384-391. doi:10.3171/2014.9.PEDS13518

9. Moon WS, Chung GH, Hong KH. Intravascular papillary endothelial hyperplasia in a vascular lesion of the paranasal sinus. Arch Pathol Lab Med. 2000;124(8):1224-1227. doi:10.5858/2000-124-1224IPEHIA

10. Lee W, Hui F, Sitoh YY. Intravascular papillary endothelial hyperplasia in an intracranial thrombosed aneurysm: $3 \mathrm{~T}$ magnetic resonance imaging and angiographical features. Singapore Med J. 2004; 45:330-333.

11. Pelosi G, Sonzogni A, Viale G. Intravascular papillary endothelial hyperplasia of the renal vein. Int J Surg Pathol. 2011;19:518-520. doi: $10.1177 / 1066896909341800$

12. Korkolis DP, Papaevangelou M, Koulaxouzidis G, Zirganos N, Psichogiou H, Vassilopoulos PP. Intravascular papillary endothelial hyperplasia (Masson's hemangioma) presenting as a soft-tissue sarcoma. Anticancer Res. 2005;25:1409-1412.

13. Reed CN, Cooper PH, Swerlick RA. Intravascular papillary endothelial hyperplasia. Multiple lesions simulating Kaposi's sarcoma. $J$ Am Acad Dermatol. 1984;10(1):110-113. doi:10.1016/S0190-9622(84) 80053-5

14. Weber FL, Babel J. Intravascular papillary endothelial hyperplasia of the orbit. Br J Ophthalmol. 1981;65:18-22. doi:10.1136/bjo.65.1.18

15. Youngerman JS. Intravascular papillary endothelial hyperplasia. Arch Otolaryngol. 1984;110:274-275.

16. Izukawa D, Lach B, Benoit B. Intravascular papillary endothelial hyperplasia in an intracranial cavernous hemangioma. Neurosurgery. 1987;21(6):939-941. doi:10.1227/00006123198712000-00029

17. Stern Y, Braslavsky D, Segal K, Shpitzer T, Abraham A. Intravascular papillary endothelial hyperplasia in the maxillary sinus. A benign lesion that may be mistaken for angiosarcoma. Arch Otolaryngol Head Neck Surg. 1991;117:1182-1184. doi:10.1001/archotol.1991.01870220130024

18. Lam CH, Farmer JP, Meagher-Villemure K, Montes JL. Masson's vegetant haemangio-endothelioma. Pediatr Neurosurg. 1995;23:9396. doi:10.1159/000120943

19. Pantanowitz L, Muc R, Spanger M, Sonnedecker H, McIntosh WA. Intravascular papillary endothelial hyperplasia (Masson's tumor) manifesting as a lateral neck mass. Ear Nose Throat $J$. 2000;79:806,809-10812. doi:10.1177/014556130007901012

20. Barras C, Olver JM, Cole C, Seet JE. Intravascular papillary endothelial hyperplasia (IPEH) mimicking a lacrimal sac mass. Eye. 2001;15 (5):685-687. doi:10.1038/eye.2001.223

21. Suh KS, Shin KS, Park IA. Intravascular papillary endothelial hyperplasia of the neck masquerading as malignancy on fine-needle aspiration cytology. Diagn Cytopathol. 2003;29:14-17. doi:10.1002/ dc. 10207 
22. Nishimoto K, Takaki M, Hirase H, Matsune S, Kurono Y. Extravascular papillary endothelial hyperplasia arising from parapharyngeal space. Auris Nasus Larynx. 2004;31(3):305-308. doi:10.1016/j.anl.2004.05.007

23. Wang XY, Namiq A, Fan F. A 55-year-old woman with a buccal mass. Intravascular papillary endothelial hyperplasia. Arch Pathol Lab Med. 2006;130(6):877-878. doi:10.5858/2006-130-877AYWWAB

24. Ucok C, Karasu HA, Orhan K, Ucok O, Tuncer N. Intravascular papillary endothelial hyperplasia and osteoma: a case report of an individual with 2 different pathologies. Quintessence Int. 2007;38: e88-e91.

25. Hooda S, Humphreys MR, Wong SW, Evans AS. Masson's pseudotumour of the ethmoid sinus - a case report. J Laryngol Otol. 2008;122:990-992. doi:10.1017/S0022215107000187

26. Schulze S, Hoerle S, Koop G, Barth PJ, Huegens-Penzel M, Strempel I. Intravascular papillary endothelial hyperplasia - a rare finding in the orbital region. Ophthalmologica. 2008;222:213-215. doi:10.1159/ 000126086

27. Güvenç MG, Dereköylü L, Korkut N, Oz F, Oz B. Intravascular papillary endothelial hyperplasia (Masson lesion) of the hypopharynx and larynx. Ear Nose Throat J. 2008;87:700-701. doi:10.1177/ 014556130808701214

28. Wang ZH, Hsin CH, Chen SY, Lo CY, Cheng PW. Sinonasal intravascular papillary endothelial hyperplasia successfully treated by endoscopic excision: a case report and review of the literature. Auris Nasus Larynx. 2009;36:363-366. doi:10.1016/j.anl.2008.06.006

29. Aggarwal E, Madge SN, Rodgers N, Selva D. Compressive effects of intravascular papillary endothelial hyperplasia. Ophthalmic Plast Reconstr Surg. 2010;26(2):122-124. doi:10.1097 IOP.0b013e3181b8e0e9

30. Yonezawa H, Hiraki A, Iyama KI, Shinohara M. Intravascular papillary endothelial hyperplasia associated with venous pool arising in the lower lip: a case report. Int $J$ Dent. 2009;2009:940686. doi: $10.1155 / 2009 / 940686$

31. Moriyama S, Kunitomo R, Sakaguchi H, et al. Intravascular papillary endothelial hyperplasia in an aneurysm of the superficial temporal artery: report of a case. Surg Today. 2011;41(10):1450-1454. doi:10.1007/s00595-010-4499-2

32. Park KK, Won YS, Yang JY, Choi CS, Han KY. Intravascular papillary endothelial hyperplasia (Masson tumor) of the skull: case report and literature review. J Korean Neurosurg Soc. 2012;52:52-54. doi: $10.3340 / \mathrm{jkns} .2012 .52 .1 .52$

33. Lee SK, Jung TY, Baek HJ, Kim SK. Destructive radiologic development of intravascular papillary endothelial hyperplasia on skull bone. J Korean Neurosurg Soc. 2012;52:48-51. doi:10.3340/ jkns.2012.52.1.48

34. Narwal A, Sen R, Singh V, Gupta A. Masson's hemangioma: a rare intraoral presentation. Contemp Clin Dent. 2013;4:397-401. doi:10.4103/0976-237X.118363

35. Miller TR, Mohan S, Tondon R, et al. Intravascular papillary endothelial hyperplasia of the skull base and intracranial compartment. Clin Neurol Neurosurg. 2013;115(10):2264-2267. doi:10.1016/ j.clineuro.2013.07.021

36. Guledgud MV, Patil K, Saikrishna D, Madhavan A, Yelamali T. Intravascular papillary endothelial hyperplasia: diagnostic sequence and literature review of an orofacial lesion. Case Rep Dent. 2014;2014:934593. doi:10.1155/2014/934593

37. Nguyen: CT, McKelvie P, Hardy TG. Subacute presentation of eyebrow intravascular papillary endothelial hyperplasia causing ophthalmic nerve compression. Clin Exp Ophthalmol. 2015;43(3):285-288. doi:10.1111/ceo.12406

38. Xu SS, Li D. Radiological imaging of florid intravascular papillary endothelial hyperplasia in the mandibule: case report and literature review. Clin Imaging. 2014;38:364-366. doi:10.1016/j.clinimag. 2013.12.006
39. Tedla M, Bežová M, Biró C, Tedlová E, Eng CY, Zeleník K. Intravascular papillary endothelial hyperplasia of larynx: case report and literature review of all head and neck cases. Otolaryngol Pol. 2014;68:200-203. doi:10.1016/j.otpol.2014.03.002

40. Shah HC, Mittal DH, Shah JK. Intravascular papillary endothelial hyperplasia (Masson's tumor) of the scalp with intracranial extension. J Pediatr Neurosci. 2014;9:260-262. doi:10.4103/1817-1745.147584

41. Mignogna C, Barca I, Di Vito A, et al. Extravascular type of intravascular papillary endothelial hyperplasia mimicking parotid gland neoplasia and the possible role of ferritin in the pathogenesis: a case report. Mol Clin Oncol. 2017;6(2):193-196. doi:10.3892/ mco.2016.1117

42. Kim D, Israel H, Friedman M, Kuhel W, Langevin CJ, Plansky T. Intravascular papillary endothelial hyperplasia manifesting as a submandibular mass: an unusual presentation in an uncommon location. $J$ Oral Maxillofac Surg. 2007;65:786-790. doi:10.1016/j. joms.2005.11.095

43. Gupta A, Chaturvedi S, Jha K, Nazir W. Intravascular papillary endothelial hyperplasia presenting as a cystic mass in the scalp with underlying bone involvement: a rare entity. Int J Appl Basic Med Res. 2017;7:269-271. doi:10.4103/ijabmr.IJABMR_360_16

44. D’Aguanno V, Ralli M, De Virgilio A, Greco A, de Vincentiis M. The role of differential diagnosis in intravascular papillary endothelial hyperplasia of the sinonasal cavity mimicking angiosarcoma: a case report. Oncol Lett. 2019;17:1253-1256. doi:10.3892/ol.2018.9717

45. Alotaibi M, Geisler V, Olze H, Knopke S. Masson tumor as a neck mass. Eur Ann Otorhinolaryngol Head Neck Dis. 2019;137(3):217218. doi:10.1016/j.anorl.2018.11.010

46. Cooke P, Goldrich D, Iloreta AM, Salama A, Shrivastava R. Intravascular papillary endothelial hyperplasia of the maxillary sinus in patient with tricuspid atresia. Head Neck Pathol. 2019;14 (3):803-807. doi:10.1007/s12105-019-01070-

47. Razek AA, Huang BY. Soft tissue tumors of the head and neck: imaging-based review of the WHO classification. Radiographics. 2011;31(7):1923-1954. doi:10.1148/rg.317115095

48. Sepahdari AR, Politi LS, Aakalu VK, Kim HJ, Razek AA. Diffusionweighted imaging of orbital masses: multi-institutional data support a 2-ADC threshold model to categorize lesions as benign, malignant, or indeterminate AJNR. Am $J$ Neuroradiol. 2014;35(1):170-175. doi:10.3174/ajnr.A3619

49. Politi LS, Forghani R, Godi C, et al. Ocular adnexal lymphoma: diffusion-weighted MR imaging for differential diagnosis and therapeutic monitoring. Radiology. 2010;256(2):565-574. doi:10.1148/ radiol.10100086

50. Nagata S, Nishimura H, Uchida M, et al. Diffusion-weighted imaging of soft tissue tumors: usefulness of the apparent diffusion coefficient for differential diagnosis. Radiat Med. 2008;26:287-295. doi:10.1007/s11604-008-0229-8

51. Bonello L, Preda L, Conte G, et al. Squamous cell carcinoma of the oral cavity and oropharynx: what does the apparent diffusion coefficient tell us about its histology? Acta Radiol. 2016;57(11):13441351. doi:10.1177/0284185115587734

52. Preda L, Conte G, Bonello L, et al. Combining standardized uptake value of FDG-PET and apparent diffusion coefficient of DW-MRI improves risk stratification in head and neck squamous cell carcinoma. Eur Radiol. 2016;26(12):4432-4441. doi:10.1007/s00330-0164284-8

53. Schnapauff D, Zeile M, Niederhagen MB, et al. Diffusion-weighted echo-planar magnetic resonance imaging for the assessment of tumor cellularity in patients with soft-tissue sarcomas. J Magn Reson Imaging. 2009;29:1355-1359. doi:10.1002/jmri.21755

54. van Rijswijk CS, Kunz P, Hogendoorn PCW, Taminiau AHM, Doornbos J, Bloem JL. Diffusion-weighted MRI in the characterization of soft-tissue tumors. J Magn Reson Imaging. 2002;15:302-307. doi:10.1002/jmri.10061 
55. Seo JW, Kim SH, Kim AY, Jeong WK, Woo JY, Park WJ. Differentiating primary hepatic angiosarcomas from hemangiomatosis and epithelioid hemangioendotheliomas using gadoxetic acidenhanced and diffusion-weighted MR imaging. Jpn $J$ Radiol. 2017;35:655-663.
56. Phinikaridou A, Andia ME, Saha P, Modarai B, Smith A, Botnar RM. In vivo magnetization transfer and diffusion-weighted magnetic resonance imaging detects thrombus composition in a mouse model of deep vein thrombosis. Circ Cardiovasc Imaging. 2013;6(3):433-440. doi:10.1161/CIRCIMAGING.112.000077

\section{Publish your work in this journal}

Reports in Medical Imaging is an international, peer-reviewed, open access journal publishing original research, reports, reviews and commentaries on all areas of medical imaging. The manuscript management system is completely online and includes a very quick and fair peerreview system, which is all easy to use. Visit http://www.dovepress. com/testimonials.php to read real quotes from published authors. 